\title{
Macronuclear Persistence of Sequences Normally Eliminated During Development in Tetrahymena thermophila
}

\author{
Theodore C. White and Sally Lyman Allen \\ Division of Biological Sciences, The University of Michigan, Ann Arbor, Michigan
}

\begin{abstract}
During conjugation in the ciliated protozoan, Tetrahymena thermophila, a somatic MACronucleus develops from the germinal MICronucleus. Ten to 20 percent of the MIC genome is eliminated during this process. Three repetitive families have been identified which have different levels of repetition in the MIC and are eliminated to different degrees in the MAC. Some members of two of these families persist in the MAC. In this study, we have looked at these persistent sequences in the MAC of cell lines from a variety of sources including several inbed strains, two sets of caryonides, caryonidal subclones, and vegetatively aged cell clones. The results suggest that the sequences that remain in the MAC have a genetic predisposition to persist. However, epigenetic variations occur as the MAC develops so that only some of the persistent sequences are actually observed in a particular MAC. Polymorphisms may be generated if alternative processing of a single MIC segment occurs. These polymorphisms can later be resolved by phenotypic assortment during vegetative growth. These facultatively persistent sequences appear to differ from sequences previously described in this organism.
\end{abstract}

Key words: eliminated DNA, facultatively persistent sequences, macronuclear development, Tetrahymena thermophila, phenotypic assortment

\section{INTRODUCTION}

DNA elimination is a normal part of development in many systems. It was first described almost 90 years ago in an ascarid worm in which one chromosome undergoes fragmentation into several smaller chromosomes with the concurrent loss of DNA [reviewed in 1]. Since then, DNA elimination has been described in a variety of systems including ciliated protozoa [2,3], nematodes [1], crustaceans [4], and

Received for publication March 7, 1985; accepted September 4, 1985.

T.C. White is now at Netherlands Cancer Institute, Plesmanlaan 121, $1066 \mathrm{CX}$ Amsterdam, The Netherlands.

Address reprint requests to Dr. Sally L. Allen, 4047 Natural Science Bldg, University of Michigan, Ann Arbor, MI 48109-1048.

(C) 1985 Alan R. Liss, Inc. 
insects [5]. Elimination is also associated with several systems of DNA rearrangements including mammalian immunoglobin switching [6], trypanosome antigenic variation [7], and yeast mating type interconversion [8]. Studies on the processes by which these eliminations occur may help our understanding of development.

DNA elimination has been shown to occur during development in the ciliated protozoan, Tetrahymena thermophila. Tetrahymena has two distinct nuclei, a small diploid micronucleus (MIC) and a large somatic macronucleus (MAC) which contains approximately 23 times as much DNA as the MIC. The MAC develops from the MIC during the sexual process of conjugation [reviewed in 9]. During conjugation, the MIC in each of the two mating cells undergoes meiosis and one of the four meiotic products is retained. This meiotic product is duplicated and the two mating cells exchange one copy of this nucleus. The two pronuclei in each cell then fuse to form a zygotic nucleus which is genetically identical in the two exconjugants. This zygotic nucleus undergoes two rounds of mitosis. One product of this nucleus becomes the MIC and is stably inherited by all the progeny of the exconjugant. Two other products of the zygotic nucleus develop independently into MACs. These two MACs exist in the one cell until the cell divides, at which time the MACs are distributed to the two daughter cells. The four daughter cells from the two exconjugants thus contain four independently formed MACs while containing four genetically identical MICs. These four cells, called caryonides, should be identical for phenotypes that are genetically determined. However, phenotypes that are determined during MAC development may vary in the four caryonides. An example of caryonidal inheritance is mating type determination. Orias [10] has proposed a molecular basis for mating type determination which involves DNA rearrangements similar to those seen for immunoglobin switching in mammals.

The large somatic MAC contains DNA molecules that are much smaller than the average size of the germinal MIC chromosomes and are derived by fragmentation during MAC development [11]. Each molecule can replicate, and except for rDNA, each of the 250-300 types of molecules is present on average in 45 copies. These autonomously replicating pieces probably correspond to the assorting "units" seen in heterozygotes [12]. If a caryonide is heterozygous for a particular trait, some of the 45 copies will contain one allele and the rest will contain the other allele. Random distribution of allelic copies in successive fissions can produce a cell with a MAC that is homozygous for one of the alleles. This phenomenon, called phenotypic assortment, occurs with the kinetics predicted from the random distribution of 45 copies of each type of assorting unit to each daughter nucleus [reviewed in 9].

DNA elimination has been shown to be a part of MAC development in Tetrahymena, first by hybridization kinetics $[3,13]$ and more recently by recombinant DNA analysis. Ten to 20 percent of the MIC genome, mostly repetitive sequences, is eliminated or underreplicated in the $\operatorname{MAC}[3,13]$. Eliminated sequences have been associated with fragmentation at the rDNA locus $[14,15]$. They have also been found $[16,17]$ associated with $\left(\mathrm{C}_{4} \mathrm{~A}_{2}\right)_{\mathrm{n}}$, a repeat which is added to the ends of MAC fragments [18]. More recently, eliminated sequences were shown to be a part of a deletion mechanism in which the two flanking sequences were rejoined after elimination [19]. This type of deletion has been shown to occur in the vicinity of the tubulin gene [20] and also for internal MIC DNA regions containing $C_{4} A_{2}$ repeats [21]. 
We have recently identified three families of eliminated sequences with different levels of repetition which are clustered at several sites in the MIC genome in different inbred strains [22]. All three families are present on a cloned piece of MIC DNA (pT 1008) derived from the progeny of a cross of strains D and D/1. pT1008 was divided into seven subclones, and they were used in naming the three families. One family (A4-A5) has three to four members in the MIC and is completely eliminated from the MAC. A second family (A2-A3) is present in approximately 30-50 copies and a third family (C-B-A1) in 200-300 copies in the MIC. Members of both the A2$\mathrm{A} 3$ and $\mathrm{C}-\mathrm{B}-\mathrm{A} 1$ families persist in the MAC genome.

Segments of DNA that are invariably eliminated in somatic nuclear development or invariably retained in all lineages have been described previously [16,17,23-25]. In the present study a third type of DNA segment is described-one that is retained in some cell lineages but eliminated in others. Such facultatively persistent sequences offer special opportunities for analysis. We were able to look for genetic and epigenetic components to persistence by examining the pattern of hybridization to MAC DNA fragments from several inbred strains, caryonides, caryonidal subclones, and vegetatively aged cell lines. The results suggest that the repertoire of persistent sequences is genetically determined in the MAC, but which sequences actually persist varies during any particular MAC's development.

\section{MATERIALS AND METHODS Cell Lines}

Table 1 lists the cell lines used in this study. The various relationships among inbred strains have been discussed $[9,26]$. Cell lines BX2 and BX6 are sister clones from one mating pair of round two of genomic exclusion of B-19755 crossed to A $\star$ III and were obtained from L. Jenkins (University of Iowa). The other B strain cell lines were derived by inbreeding clones of different mating type from the same mating pair. Cell lines B7N and B4 were obtained from D.L. Nanney (University of Illinois) and had been frozen from about 1968 to 1974 . Cell line B7B is the same cell line as B7N except that it was never frozen and was obtained from P.J. Bruns (Cornell University). Cell lines B7 (N or B) and B4 are caryonides that differ in mating type and were randomly isolated from the same mating pair. The construction of strain $D / 1$, congenic with strain D, has been described [27]. All strains except for BX2 and BX6 were originally constructed in this laboratory.

Two sets of caryonides (31A-31D, 42A-42D) were selected randomly from a number of partial and complete sets isolated from a cross of $D \times D / 1$. Each set of four caryonides was separated, such that $\mathrm{A}$ and $\mathrm{B}$ are the sister caryonides from one exconjugant, and $\mathrm{C}$ and $\mathrm{D}$ are the sister caryonides of the other exconjugant. After 35 fissions, each caryonide from the 31 set was subcloned: single cells were randomly isolated from each of the four caryonidal populations. Three cell lines were used from one caryonide (31A), while only a single cell line was used from each of the other three caryonides. This first set of subclones was allowed to divide for 40 more fissions, or a total of 75 fissions. Then, a second set of subclones was made by cloning the first set of subclones: single cells were isolated from one of the descendant populations of three of the caryonides. Three cell lines were used from the 31A descendant, while only one cell line was used from each of the descendants of 31B 
TABLE 1. Tetrahymena thermophila Cell Lines Used in This Study

\begin{tabular}{|c|c|c|}
\hline $\begin{array}{l}\text { Type of } \\
\text { strain }\end{array}$ & \multicolumn{2}{|c|}{$\begin{array}{c}\text { Designation of lineage } \\
\text { (names in parentheses are used in text) }\end{array}$} \\
\hline Inbred strains & $\begin{array}{l}\text { A-17686 (A) } \\
\text { B-2079X2 (BX2) } \\
\text { B-2079X6 (BX6) } \\
\text { B-18687N (B7N) } \\
\text { B-18687B (B7B) }\end{array}$ & $\begin{array}{l}\text { B-18684 (B4) } \\
\text { B-18684b (Bb) } \\
\text { C2-4683(C2) } \\
\text { C3-3685(C3) } \\
\text { D-25772a (D) } \\
\text { D/1(I })-5771(\mathrm{D} / 1)^{\mathrm{a}}\end{array}$ \\
\hline $\begin{array}{l}\text { Caryonides from a } \\
\text { cross } \mathrm{D} \times \mathrm{D} / 1\end{array}$ & $\begin{array}{l}82-2-31 A(31 A) \\
82-2-31 B(31 B) \\
82-2-31 C(31 C) \\
82-2-31 D(31 D)\end{array}$ & $\begin{array}{l}82-2-42 \mathrm{~A}(42 \mathrm{~A}) \\
82-2-42 \mathrm{~B}(42 \mathrm{~B}) \\
82-2-42 \mathrm{C}(42 \mathrm{C}) \\
82-2-42 \mathrm{D}(42 \mathrm{D})\end{array}$ \\
\hline $\begin{array}{l}\text { Subclones of caryonides } \\
\text { (first subcloning at } \\
35 \text { fissions) }\end{array}$ & $\begin{array}{l}31 \mathrm{~A}-1 \\
31 \mathrm{~A}-2 \\
31 \mathrm{~A}-3\end{array}$ & $\begin{array}{l}31 \mathrm{~B}-2 \\
31 \mathrm{C}-2 \\
31 \mathrm{D}-2\end{array}$ \\
\hline $\begin{array}{l}\text { Subclones of caryonides } \\
\text { (sccond subcloning at } \\
75 \text { fissions) }\end{array}$ & $\begin{array}{l}31 \mathrm{~A}-1-\mathrm{a} \\
31 \mathrm{~A}-1-\mathrm{b} \\
31 \mathrm{~A}-1-\mathrm{c}\end{array}$ & $\begin{array}{l}31 B-2-a \\
31 D-2-a\end{array}$ \\
\hline $\begin{array}{l}\text { Subclones of caryonides } \\
\text { (third subcloning at } \\
115 \text { fissions) }\end{array}$ & $\begin{array}{l}31 A-1-a-4 \\
31 A-1-a-5 \\
31 A-1-a-6\end{array}$ & $\begin{array}{l}31 \mathrm{~B}-2-\mathrm{a}-7 \\
31 \mathrm{D}-2-\mathrm{a}-8\end{array}$ \\
\hline $\begin{array}{l}\text { Old cell lines from a } \\
\text { cross } \mathrm{D} \times \mathrm{D} / 1 \\
\quad \text { (approximately } 1,000 \\
\text { fissions old) }\end{array}$ & $\begin{array}{l}75-163-3 C(3 C) \\
75-163-14 C(14 C) \\
75-163-18 A(18 A)\end{array}$ & $\begin{array}{l}75-163-19 A(19 A) \\
75-163-20 B(20 B) \\
75-163-21 C(21 C)\end{array}$ \\
\hline Young population & DI21481 (DI) & \\
\hline
\end{tabular}

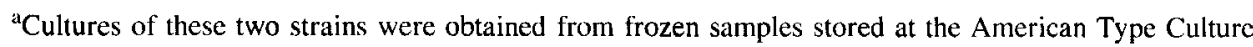
Collection (ATCC 30845 and ATCC 30847 , respectively).

and 31D. This second set of subclones was further cloned after 40 more fissions, or a total of 115 fissions. Single cells were isolated from one of the descendants of $31 \mathrm{~A}$, $31 \mathrm{~B}$, and $31 \mathrm{D}$, three cell lines being used for the 31A lineage, and one cell line for each of the 31B and 31D lineages. All three sets of subclones are listed in Table 1 and labeled to illustrate how they descended from the original caryonide set.

The vegetatively aged, or "old," cell clones were also obtained from a cross of $\mathrm{D} \times \mathrm{D} / 1$. From this cross, made at the end of 1975 (A75-163), individual mating pairs were placed into separate wells of depression slides, and caryonides were randomly isolated. Serial cloning was carried out for each cell line: every 13 fissions, a single cell was isolated and allowed to divide. After ten serial isolations, the cell line was placed in tube culture. The resulting cell lines were subcultured bimonthly at $23^{\circ} \mathrm{C}(1976-1978)$ and then monthly $(1979-1985)$ at $16^{\circ} \mathrm{C}$, and are now about 1,000 fissions old. Subclones of the old cell clones were obtained from tubed populations when they were between 900 and 1,000 fissions old.

\section{Growth of Cultures, Nuclear Isolations, and DNA Preparations}

Cultures are maintained at $16^{\circ} \mathrm{C}$ in $1 \%$ proteose peptone and are now subcultured monthly. Growth of cultures for nuclear preparations has been described [28]. 
MACs were purified by the use of repeated Percoll gradients until the nuclear cross contamination was less than $1 \mathrm{MIC}$ in $200 \mathrm{MACs}$ [28]. After nuclear isolation, DNA was purified by $\mathrm{CsCl}$ gradient centrifugation as already outlined [28].

\section{Plasmid Preparation and Nick Translation}

The plasmids that were used in this study include pT1008 and its seven subclones. pT 1008 contains MIC DNA derived from the progeny of a cross of $D \times D / 1$. It was selected for its smaller size from a group of clones that gave an intense reaction during colony hybridization to a probe of total MIC DNA but a minimal reaction when probed with total MAC DNA [22]. The seven subclones, pT1008-A1, pT1008A2, pT1008-A3, pT1008-A4, pT1008-A5, pT1008-B, and pT1008-C, will be referred to in the text as A1, A2, A3, A4, A5, B, and C. Their location along the restriction map of pT1008 is shown in Figure 1. Plasmid DNA was isolated by a modification of the SDS/high salt cleared lysate procedure [29], followed by $\mathrm{CsCl} / \mathrm{ethidium}$ bromide gradient centrifugation in a vertical rotor. DNA was labeled in vitro with $\alpha^{32} \mathrm{P}$ dATP by a modified nick-translation procedure routinely giving about $10^{8}$ $\mathrm{cpm} / \mu \mathrm{g}[30,31]$. Unincorporated radioactive nucleotides were removed from the samples by chromatography through Sephadex G-50.

\section{Restriction Enzyme Digestion and Gel Electrophoresis}

Digestions using tenfold excess of enzyme were carried out by the method of Maniatis et al [32] with restriction enzymes purchased from Bethesda Research Laboratories, New England Biolabs, or Amersham. Submarine gel electrophoresis was carried out with 12-inch long gels and a Tris borate buffer system containing ethidium bromide [33-35] using appropriate size markers, either $\phi X 174$ DNA digested with Hind II or $\lambda$ DNA digested with Ava I and Bgl II. $\lambda$ DNA digested with Ava I and $\mathrm{Bgl}$ II generates fragments of the following sizes (in $\mathrm{kb}$ ): 14.9, 8.8, 5.5, $4.3,3.7,2.44,2.23,1.93,1.64,1.44,1.07,0.54$ and 0.48 plus a few smaller ones. Dashes in each figure were estimates of size and are derived from standard curves using the above size markers.

\section{Genomic Blotting and Hybridization}

DNA was transferred from the gels to nitrocellulose filters by the method of Southern [36] with modifications. Prehybridization, hybridization, and washing were all done at $62^{\circ} \mathrm{C}$. These conditions were chosen due to the $25 \% \mathrm{GC}$ content of Tetrahymena DNA [37]. The filters were presoaked in $3 \times$ SSC for one-half hour

\section{PT 1008}

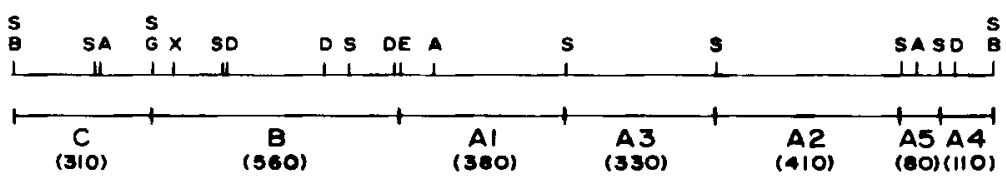

Fig. 1. The restriction map of pT 1008 and its subclones. The pT 1008 map was constructed by analysis of the plasmid and its subclones. The sizes of the individual subclones are given in base pairs. Restriction sites are designated as follows: $\mathbf{A}=$ Alu $\mathbf{I}, \mathbf{B}=\mathrm{Bam} \mathrm{HI}, \mathrm{D}=$ Dde I, $\mathbf{E}=$ Eco RI, $\mathbf{G}=\mathrm{Bgl}$ II, $\mathrm{S}=$ Sau $3 A$ (or Mbo I), and X = Xba I. 
( $\mathrm{SSC}=0.15 \mathrm{M} \mathrm{NaCl}, 0.015 \mathrm{M}$ sodium citrate $)$ and then prehybridized for five hours in $10 \times$ Denhardt's solution [38] with $3 \times \mathrm{SSC}, 0.1 \% \mathrm{SDS}$, and $25 \mu \mathrm{g} / \mathrm{ml}$ of denatured calf thymus DNA. Then the prehybridization mixture was replaced with fresh denatured prehybridization and probe mixture $\left(1-2 \times 10^{6} \mathrm{cpm} / \mathrm{ml}\right)$, and hybridization was continued for at least 36 hours. Filters the size of a full sized gel received $4 \times 10^{7}$ cpm. The filters were washed six times in $2 \times$ SSC, $1 \%$ SDS for 20 minutes, then once in $0.2 \times \mathrm{SSC}, 1 \% \mathrm{SDS}$ for 30 minutes, and finally in $2 \times \mathrm{SSC}$ for ten minutes. The filters were dried for two hours and exposed to Kodak XAR-5 film at $-80^{\circ} \mathrm{C}$ with an intensifying screen. The length of exposure depended on the amount of radioactivity on the filter.

\section{RESULTS}

\section{The MACs of Inbred Strains Probed With pT1008}

MAC DNA was isolated from each of the cell lines of the various inbred strains listed in Table 1. These MAC DNAs were digested with Mbo I, an isoschizomer of Sau 3A, to separate fragments with homologies to different subclones, since many of the subclones are separated by Mbo I (Sau 3A) sites (See Fig. 1 for a restriction map of pT1008 and the location of the seven subclones). The DNA fragments were separated by electrophoresis through agarose gels and blotted to nitrocellulose. The filters were probed with pT1008 and its seven subclones. When the filter was probed with pT1008, a great deal of variation was observed in the banding pattern of the MAC DNAs from different cell lines (Fig. 2). Genomic blots probed with pT1008's subclones allowed us to assign each fragment to the subclone which hybridizes to that fragment. The results are shown in Tables 2 and 3.

All except two of the MAC fragments hybridizing with pT1008 were assigned to one or more of the subclones. The two exceptions are included in Table 2. One of the fragments is $4.7 \mathrm{~kb}$ and is present in cell lines $\mathrm{D}$ and $\mathrm{D} / 1$. The other fragment is

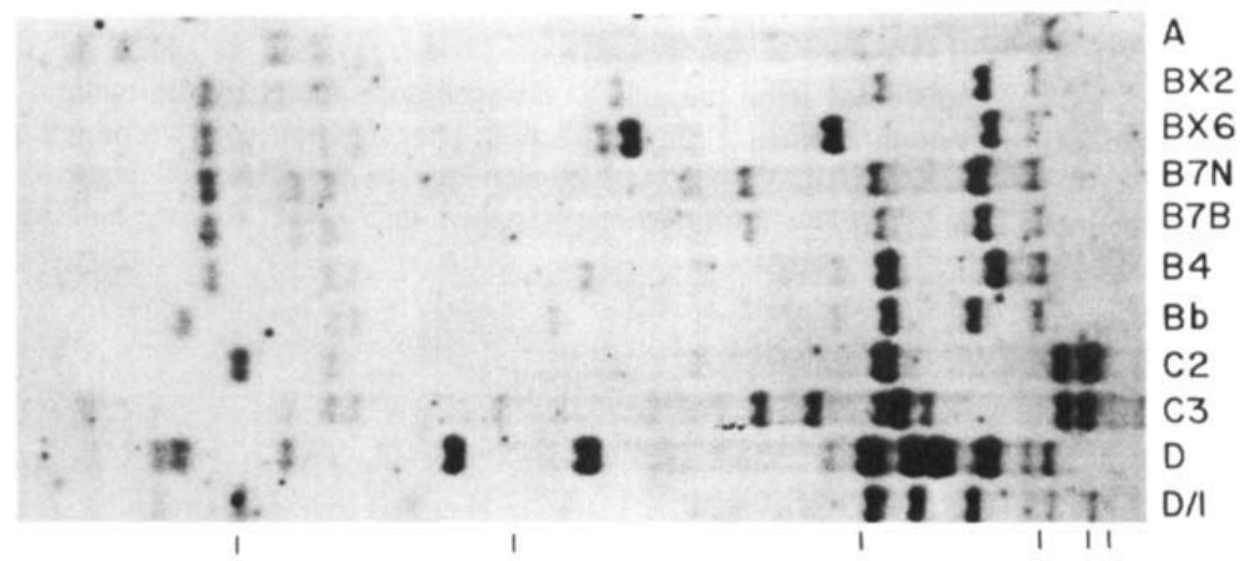

Fig. 2. Genomic blots of the MAC DNAs from various inbred strains probed with pT 1008. Each lane contains $5 \mu \mathrm{g}$ of MAC DNA digested with Mbo I. The DNAs were run through a $1 \%$ agarose gel and blotted. The cell line designations are listed in Table 1. The dashes at the bottom represent 10, 7.5, 5.0, $2.5,1.0$, and $0.5 \mathrm{~kb}$ (from right to left). 
$2.4 \mathrm{~kb}$ and is present in cell lines $\mathrm{B} 4, \mathrm{Bb}$, and $\mathrm{D}$. A fragment of similar size $(2.4 \mathrm{~kb})$ occurs in cell line BX6 where it hybridizes to A3.

\section{The A4-A5 Family}

The A4-A5 family is present in three to five copies in the MIC genome and is totally eliminated from the MAC [22]. This family is defined by the subclones A4 and A5 from pT1008 (see Fig. 1). The family is present in a similar arrangement in the MIC of several inbred strains. This study confirmed that the A4-A5 family is totally eliminated from the MACs of several inbred strains since subclones A4 and

TABLE 2. A2-A3 Bands in the MACs of Inbred Strains

\begin{tabular}{|c|c|c|c|c|c|c|c|c|c|c|c|}
\hline \multirow{3}{*}{$\begin{array}{l}\text { Size of } \\
\text { Mbo I } \\
\text { band (kb) }\end{array}$} & \multirow[b]{3}{*}{ A } & \multicolumn{10}{|c|}{ Inbred strains } \\
\hline & & \multicolumn{6}{|c|}{ B } & \multirow[b]{2}{*}{$\mathrm{C} 2$} & \multirow[b]{2}{*}{$\mathrm{C} 3$} & \multirow[b]{2}{*}{ D } & \multirow[b]{2}{*}{$\mathrm{D} / 1$} \\
\hline & & $\mathrm{BX} 2$ & BX6 & B $7 N$ & B7B & B4 & $\mathrm{Bb}$ & & & & \\
\hline$>20$ & & & & & & & & & 2 & & \\
\hline 7.2 & & & & & & & & 2 & 2 & & 2 \\
\hline 5.8 & 2 & & & & & & & 2 & 2 & & \\
\hline 5.3 & & & & & & & & & & 2 & 2 \\
\hline 5.2 & & 2 & 2 & 2 & 2 & 2 & 2 & & & & \\
\hline 4.7 & & & & & & & & & & $\dagger$ & $\dagger$ \\
\hline 4.1 & & & 2,3 & & & 2 & & & & & \\
\hline 4.0 & & 2,3 & & 2 & 2 & & & & & 2,3 & \\
\hline 3.8 & & & & & & & 2 & & & & 2,3 \\
\hline 3.1 & & & & & & & & & 2 & & \\
\hline 2.8 & & & & & & & & & 3 & & \\
\hline 2.7 & & 2 & & 2 & 2 & 2,3 & 3 & 2,3 & 2 & 2 & 2 \\
\hline 2.6 & 2 & 2 & & & & & & & & & \\
\hline 2.4 & & & 3 & & & $*$ & * & & & $*$ & \\
\hline 2.2 & & & & & & & & & 2 & & \\
\hline 1.90 & & & & 2 & 2 & & & & 2 & & \\
\hline 1.65 & & 2 & 2 & 2 & 2 & 2 & 2 & 2 & & & \\
\hline 1.40 & & & 2,3 & & & & & & & & \\
\hline 1.35 & & 2 & & & & & & & & & \\
\hline 1.30 & & & 2 & & & & & & & & \\
\hline 1.20 & & & & & & 2 & & & & & \\
\hline 1.10 & & & & & & & 2 & & & & \\
\hline 0.68 & & & 2 & & & 2 & 2 & & 2 & & \\
\hline 0.65 & 2 & 2 & 2 & 2 & 2 & 2 & 2 & 2 & 2 & & \\
\hline 0.60 & & & & 2 & 2 & & & & & & \\
\hline 0.57 & 2 & 2 & 2 & & & & & & & & \\
\hline 0.54 & & & & 2 & 2 & & & & & & \\
\hline 0.51 & & & & & & & & 2 & & & 3 \\
\hline 0.48 & & 2,3 & 2,3 & 2,3 & 2,3 & 2,3 & & & & & 2 \\
\hline 0.45 & & & & & & & 2,3 & & & & \\
\hline $\begin{array}{r}\text { No. } A 2 \\
\text { bands }\end{array}$ & 4 & 9 & 9 & 9 & 9 & 8 & 7 & 6 & 9 & 3 & 5 \\
\hline $\begin{array}{r}\text { No. A3 } \\
\text { bands }\end{array}$ & 0 & 2 & 4 & 1 & 1 & 2 & 2 & 1 & 1 & 1 & 2 \\
\hline $\begin{array}{l}\text { Total } \\
\text { number }\end{array}$ & 4 & 11 & 13 & 10 & 10 & 10 & 9 & 6 & 10 & 4 & 7 \\
\hline
\end{tabular}

$2=$ band detected with subclone $\mathrm{A} 2 ; 3=$ band detected with subclone $\mathrm{A} 3 ; *, \dagger=$ bands detected by pT 1008 but not detected by any subclone. 
TABLE 3. C-B-A1 Bands in the MACs of Inbred Strains*

\begin{tabular}{|c|c|c|c|c|c|c|}
\hline \multirow{2}{*}{$\begin{array}{l}\text { Size of Mbo I } \\
\text { band: (in kb) }\end{array}$} & \multicolumn{2}{|c|}{$C 3^{\mathrm{a}}$} & \multicolumn{2}{|c|}{$D^{a}$} & \multicolumn{2}{|c|}{$\mathrm{D} / 1^{\mathrm{a}}$} \\
\hline & $\mathrm{B}^{\mathrm{b}}$ & $A 1^{\mathrm{b}}$ & $\mathrm{B}^{\mathrm{b}}$ & $\mathrm{A} 1^{\mathrm{b}}$ & $\mathrm{B}^{\mathrm{b}}$ & $\mathrm{Al}{ }^{\mathrm{b}}$ \\
\hline 3.8 & & & + & + & & \\
\hline 3.3 & & & + & + & & \\
\hline 3.1 & & & & + & & \\
\hline 3.0 & & & + & + & + & + \\
\hline 2.6 & & & & + & & + \\
\hline 1.2 & & & & + & & \\
\hline 0.98 & & + & & & & \\
\hline 0.88 & & & & + & & \\
\hline 0.58 & & + & & & & \\
\hline 0.57 & & & + & & & \\
\hline 0.47 & $\S$ & & $\S$ & & $\S$ & \\
\hline 0.44 & & & + & & & \\
\hline 0.40 & $\S$ & & $\S$ & & $\S$ & \\
\hline 0.35 & $\S$ & & $\S$ & & $\S$ & \\
\hline Total number & 3 & 2 & 8 & 7 & 4 & 2 \\
\hline
\end{tabular}

${ }^{*}+=$ band present; $\S=$ these three bands are very faint and are the only $\mathrm{B}$-probe bands present in the cell lines of other inbred strains examined, including A, BX2, BX6, B7N, B7B, B4, Bb, and C2. (None of these strains hybridize to probe Al.)

${ }^{a}$ Inbred strain.

${ }^{\mathrm{b}}$ Probe.

A5 do not hybridize to any fragments in the MAC of any of the cell lines that were tested.

\section{The A2-A3 Family}

The A2-A3 family is a repetitive family that is present in approximately $30-50$ copies in the MIC and one to five copies persist in the MAC of cell line DI [22]. It is defined by subclones A2 and A3 of pT1008 (see Fig. 1). It is present in a similar arrangement in the MIC of several inbred strains. The MAC fragments identified in the pT1008 genomic blot that were assigned to DNA subclones A2 and A3 are listed in Table 2. The total number of MAC fragments that hybridize to the A2-A3 family can vary from four to 13 , depending on the cell line. Each subclone also varies in the number of fragments that hybridize with it; A2 hybridizes with three to nine fragments, A3 hybridizes with zero to four fragments. Not only is there variation in number, but there is a great deal of variation in the banding patterns of A2 and A3 in the different cell lines tested.

The cell lines that are most closely related are $\mathrm{B} 7 \mathrm{~N}$ and $\mathrm{B} 7 \mathrm{~B}$, which are samples of the same original cell line obtained from two different laboratories. B7N and B7B have identical banding patterns for $\mathrm{A} 2$ and $\mathrm{A} 3$; thus, no alteration of this family's sequences appears to have occurred in the MACs since the two cell lines were separated. The cell lines with the next closest relationship are BX2 and BX6, which are sister cells from round 2 of genomic exclusion. The consequence of round 2 of genomic exclusion is two genetically identical cells homozygous for all loci [reviewed in 9]. However, the cells form their MACs independently. Therefore, it is interesting that BX2 and BX6 are different in their banding pattern for the A2-A3 family. 
Some of the similarities in banding pattern reflect the relationships of the inbred strains. The six cell lines from inbred strain B have similar banding patterns for the A2-A3 family. For instance, the 5.2-, 1.65-, 0.65-, and $0.48 / 0.45-\mathrm{kb}$ bands are present in all the B strain cell lines. The C2 and C 3 cell lines are closely related, as are their banding patterns, including the $72.2-$ and $5.8-\mathrm{kb}$ bands. Finally, D and D/1 are congenic strains [27] and their banding patterns are similar, as seen with the 5.3-, 4.7-, and 4.0/3.8-kb bands. Inbred strains A, B, C2, C3, D, and D/1 are variously related to each other and this is reflected in their banding patterns when their MAC DNAs are probed with the A2-A3 family.

\section{The C-B-A1 Family}

The C-B-A1 family, which is present in $200-300$ copies in the MIC genome, is only present in one copy in the MAC of cell line DI [22]. The family is defined by subclones C, B, and A1 from pT1008 (see Fig. 1). Subclone C was found to be MIC specific [22]. In this study, subclone $C$ did not hybridize to any fragments in the MACs of any of the cell lines tested. However, subclones B and Al hybridized to a few fragments in the MACs of some (or all) the inbred strains tested. As shown in Table 3 subclone B hybridizes very faintly to three small fragments $(0.47,0.40$, and $0.35 \mathrm{~kb}$ ) in all the cell lines investigated. It hybridizes strongly to five other fragments in cell line $\mathrm{D}$; one of these fragments $(3.0 \mathrm{~kb})$ is also present in cell line $\mathrm{D} / 1$. Three of the five fragments in cell line D also hybridize to subclone A1. Subclone A1 hybridizes to several fragments in cell lines $\mathrm{C} 3, \mathrm{D}$, and $\mathrm{D} / 1$. Two fragments $(3.0$ and $2.6 \mathrm{~kb}$ ) in cell line $\mathrm{D} / 1$ are part of the set of fragments seen in cell line $\mathrm{D}$. A1 does not hybridize to any fragments in the MACs of the cell lines from inbred strains $A$, $\mathrm{B}$, or C2.

\section{Clonal Analysis Of Persistent MAC Fragments in the Hybrid of Strains $D \times D / 1$}

To further investigate the process by which these fragments remain in the MAC, several cell lines were prepared from crosses of $D \times D / 1$. One of the reasons for using this cross is that these two strains contain a number of fragments that hybridize to DNA subclones $\mathrm{A} 1$ and $\mathrm{B}$, whereas inbred strains $\mathrm{A}, \mathrm{B}$, and $\mathrm{C} 2$ do not contain fragments that hybridize to A1. The cell lines that were prepared included two sets of caryonides, various subclones of one of the sets of caryonides, and old cell clones which are about 1,000 fissions old. MAC DNAs were prepared from these cell lines and used in genomic blots which were probed with the DNA subclones of interest.

\section{Caryonidal Inheritance of MAC Fragments}

To determine how much of the variability seen in the A2-A3 family is epigenetically determined during MAC formation, DNA subclones A2 and A3 were used as probes against genomic blots of the caryonides and caryonidal subclones. The results are shown in Figure 3. Many of the Mbo I fragments that hybridize to A3 also hybridize to A2. Although there are several bands in common between caryonides within one set and caryonides from different sets, there are variations in the banding patterns of the MAC DNAs within both sets of caryonides for both A2 and A3. There were also variations in the banding patterns within various caryonidal subclones: some bands were lost while new bands appeared (data not shown). However, the overall patterns were similar during vegetative aging. 

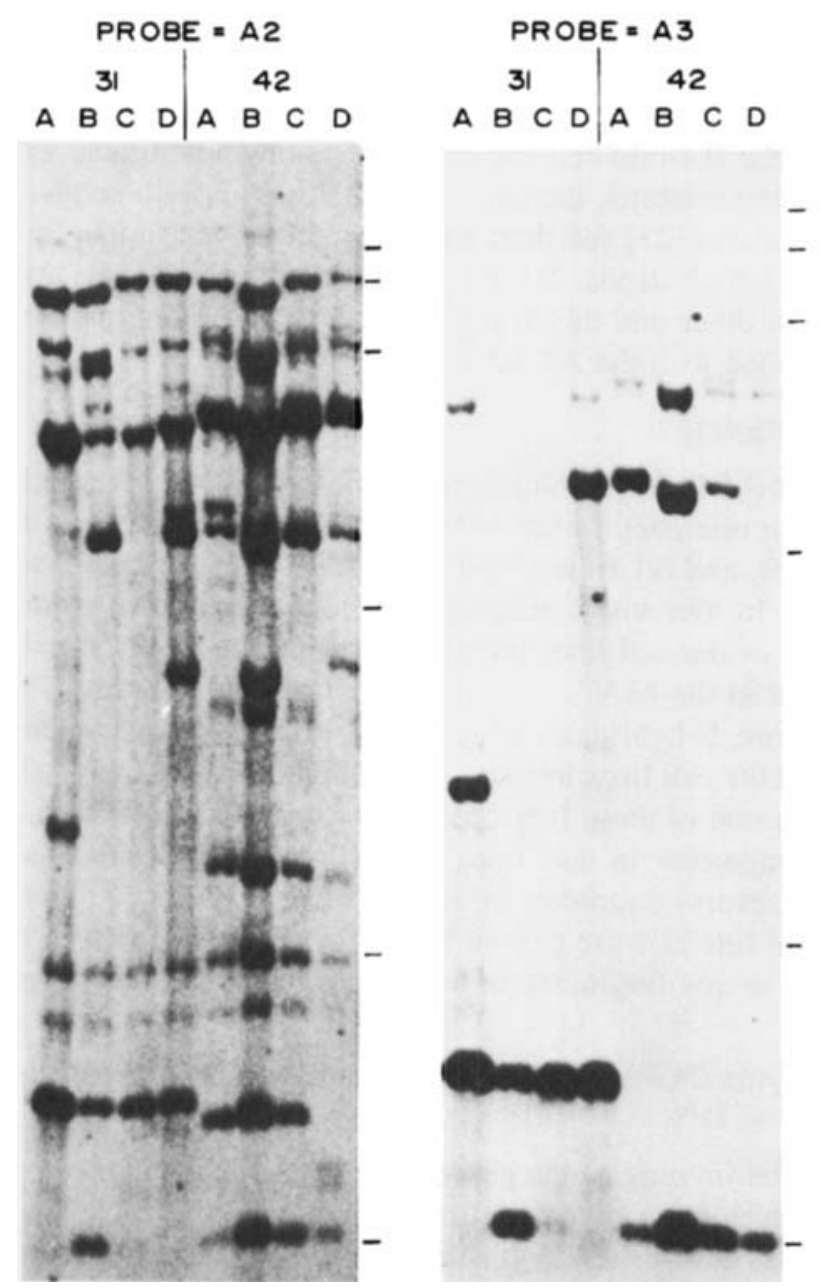

Fig. 3. Genomic blots of the two sets of caryonides probed with DNA subclone A2 and A3. Each lane contains $5 \mu \mathrm{g}$ of MAC DNA digested with Mbo I. The DNAs were run through a $1 \%$ agarose gel and blotted. The two sets of caryonides are listed in Table 1 . The dashes at the right represent 10.0, 7.5, 5.0, $2.5,1.0$, and $0.5 \mathrm{~kb}$.

DNA subclone A1 was also used as a probe against genomic blots of MAC DNAs from the caryonides and caryonidal subclones. The Mbo I banding patterns of the caryonides are shown in Figure 4. Here, major variations are seen among the caryonides in both the 31 and 42 sets. A1 hybridizes to a single but different-sized fragment in each of caryonides 31A, 31B, 31D, and 42D. It hybridizes to several different-sized fragments in caryonides $42 \mathrm{~A}, 42 \mathrm{~B}$, and $42 \mathrm{C}$. There are also variations in the subclones of the 31 set of caryonides using Hind III digests of the MAC DNAs (Fig. 5). The fragments in $31 \mathrm{~A}$ and $31 \mathrm{~B}$ appear to be similar in size (all are about 5.2 $\mathrm{kb}$ in Hind III digests) and they persist in all the caryonidal subclones of $31 \mathrm{~A}$ and $31 \mathrm{~B}$ that were investigated. DNA subclone A1 also hybridizes to a fragment in caryonidal subclone $31 \mathrm{C}-2$ (5.2 kb in Hind III digests) that is not detectable in caryonide $31 \mathrm{C}$. 


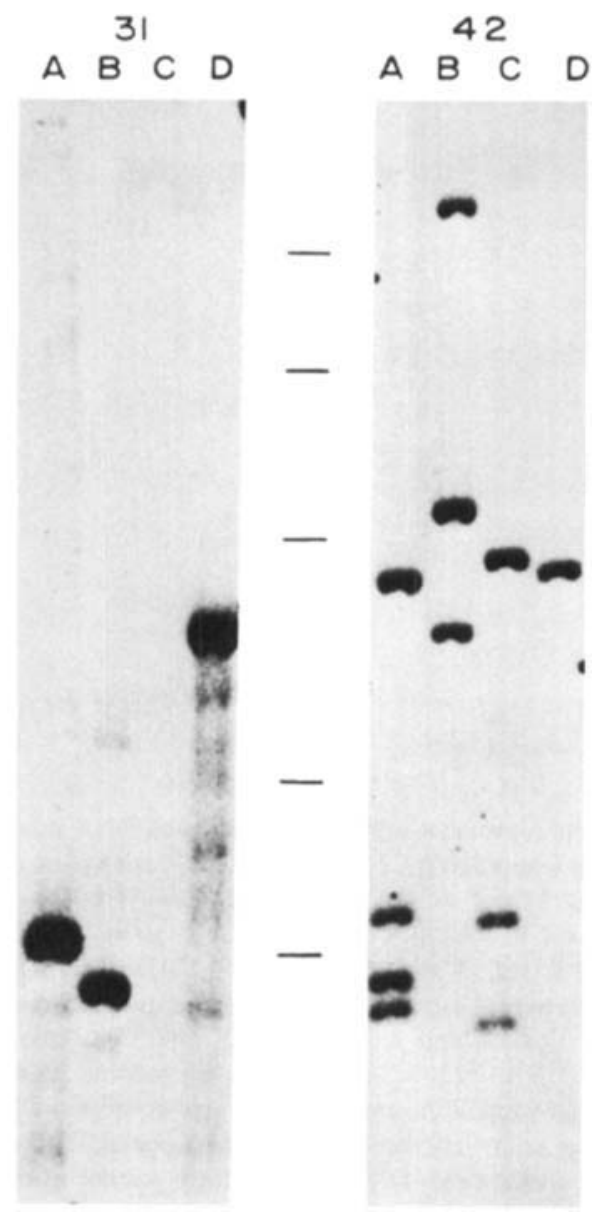

Fig. 4. Genomic blots of the two sets of caryonides probed with DNA subclone A1. This figure is similar to Figure 3 except that the caryonides were probed with A1. Dashes represent $2.5,2.0,1.5,1.0$, and $0.75 \mathrm{~kb}$.

Finally, A1 hybridizes to a fragment (1.46 kb in Hind III digests) in 31D and 31D-2. However, this fragment is not detected in subsequent subclones, 31D-2-a and 31D-2a-5, but a new fragment which is larger in size is present in its place.

DNA subclone B was not used in these analyses because it hybridizes to fragments that are either present in all the inbred strains (see Table 3: the very faint Mbo I bands at $0.47,0.40$, and $0.35 \mathrm{~kb}$ ) or are the same size as fragments that hybridize to DNA subclone Al (Mbo I bands at 3.8,3.3, and 3.0 kb in strain D and $3.0 \mathrm{~kb}$ in strain $\mathrm{D} / 1)$.

\section{Persistent Fragments in Old Cell Clones}

MAC DNA was prepared from six cell lines which are about 1,000 fissions old and were last subcloned at 130 fissions. p T 1008 and its subclones were used as probes against genomic blots of these DNAs digested with Mbo I. The genomic blot probed 


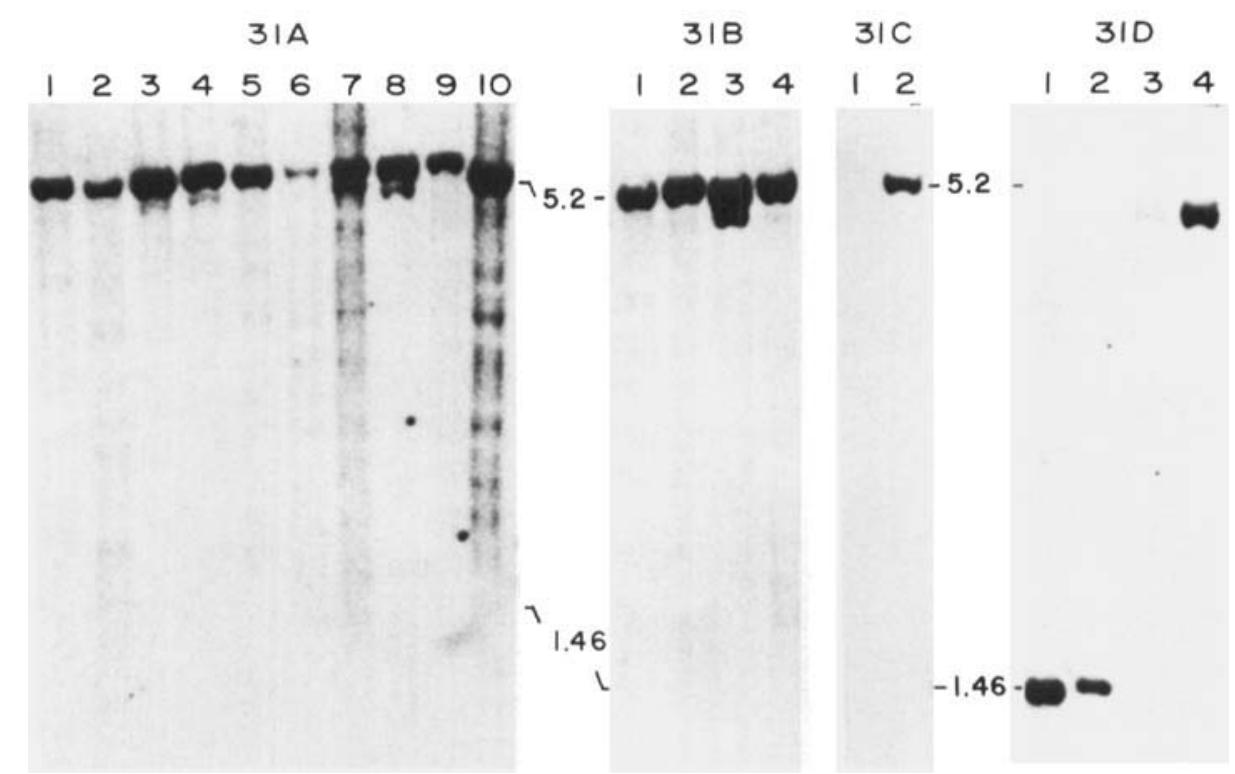

Fig. 5. Genomic blots of the caryonidal subclones probed with DNA subclone A1. Each lane contained $5 \mu \mathrm{g}$ of MAC DNA digested with Hind III. Caryonide $31 \mathrm{C}$ did not have a detectable band. The cell lines used in each series are listed: $31 \mathrm{~A}: 1=31 \mathrm{~A}, 2=31 \mathrm{~A}-1,3=31 \mathrm{~A}-1-\mathrm{a}, 4=31 \mathrm{~A}-1-\mathrm{a}-4,5=31 \mathrm{~A}-1-\mathrm{a}-$ $5,6=31 \mathrm{~A}-1-\mathrm{a}-6,7=31 \mathrm{~A}-1-\mathrm{b}, 8=31 \mathrm{~A}-1-\mathrm{c}, 9=31 \mathrm{~A}-2,10=31 \mathrm{~A}-3 ; 31 \mathrm{~B}: 1=31 \mathrm{~B}, 2=31 \mathrm{~B}-2$, $3=31 \mathrm{~B}-2-\mathrm{a}, 4=31 \mathrm{~B}-2-\mathrm{a}-7 ; 31 \mathrm{C}: 1=31 \mathrm{C}, 2=31 \mathrm{C}-2 ; 31 \mathrm{D}: 1=31 \mathrm{D}, 2=31 \mathrm{D}-2,3=31 \mathrm{D}-2-\mathrm{a}$, $4=31 \mathrm{D}-2-\mathrm{a}-8$. Background hybridization in all lanes is due to MIC contamination. There are distinct extra bands in 31A, lanes 3, 4, 7, and 8; 31B, lane 3; and 31D, lane 4. These bands are plasmid contamination of the MAC DNA. This has been shown by genomic blots probed with pBR322. New MAC DNAs could be isolated without the contamination. However, the DNAs that were used here were isolated much closer to the time that the cell line was isolated. Therefore, they better reflect the composition of the cell line at that time. DNAs are routinely screened for plasmid contamination using genomic blots which are probed with pBR322. No contamination has been detected since these caryonidal subclones were made. All other DNAs discussed in this paper are free of plasmid contamination.

with pT1008 is shown in Figure 6. Genomic blots probed with each of the DNA subclones allowed us to assign each fragment to the DNA subclone which hybridized to it. Most of the bands in the blot hybridized to DNA subclone A2.

The A2-A3 family hybridizes to several fragments in the MAC of the old cell clones. DNA subclone A3 hybridizes to two fragments (1.46 and $0.57 \mathrm{~kb}$ in Mbo I digests). The 1.46-kb fragment is present in two of the six old cell lines, while the $0.57-\mathrm{kb}$ fragment is present in the other four old cell lines. Despite the fact that DNA subclone A2 hybridizes to several fragments in each of the old cell lines, the banding pattern of each cell line is distinct.

The C-B-Al family hybridizes to a few fragments in the old cell clones. DNA subclone B hybridizes to three very faint fragments $(0.47,0.40$, and $0.35 \mathrm{~kb})$ that are present in all the inbred strains; it also hybridizes to a $3.0-\mathrm{kb}$ fragment in four of the six cell lines. DNA subclone A1 hybridizes to two fragments (3.0 and $2.6 \mathrm{~kb})$ in the same four old cell lines, but it does not hybridize to any fragments in the other two cell lines. The 3.0-kb fragment appears to hybridize to both A1 and B. 


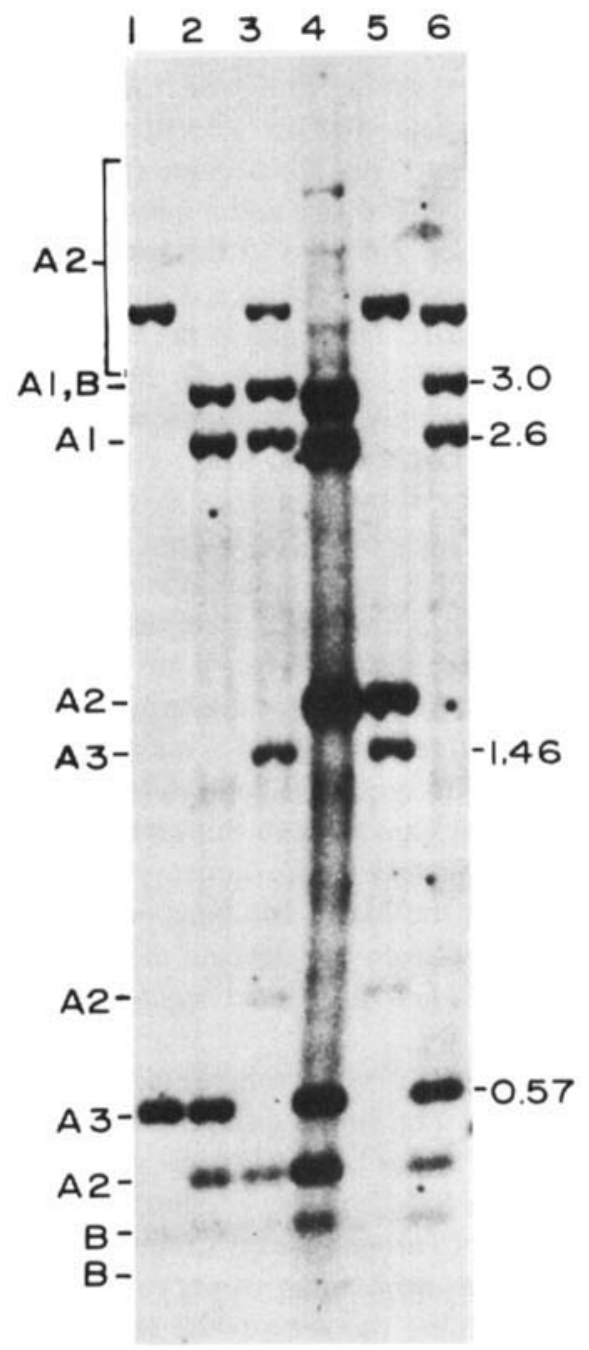

Fig. 6. Genomic blots of six old cell lines probed with pT 1008. Each lane contains $5 \mu \mathrm{g}$ of MAC DNA digested with Mbo I. The six old cell lines are listed in Table 1. $1=3 \mathrm{C} ; 2=14 \mathrm{C} ; 3=18 \mathrm{~A}, 4=19 \mathrm{~A}$; $5=20 B ; 6=21 \mathrm{C}$. Similar genomic blots were done with the DNA subclones of pT 1008 . Each band in this genomic blot could then be assigned to a DNA subclone. Most of the visible bands could be assigned to DNA subclone A2. Furthermore, other fainter bands were visible in the A2 genomic blot. These fainter bands were as variable as the bands seen in this blot. Bands which are referred to in the text are labeled with their size (in $\mathbf{k b}$ ) on the right side of the blot. The $0.35-\mathrm{kb}$ B fragment is not visible in this genomic blot.

\section{DISCUSSION}

Three types of DNA segments have now been described in terms of their behavior during MAC development in Tetrahymena thermophila: those that are invariably eliminated $[16,17,23]$, those that are retained in all cell lineages $[24,25]$, and those that are retained in some cell lineages but eliminated in others [this report; 24]. Facultatively persistent sequences as well as those totally eliminated are found 
together on MIC DNA clone pT1008. This clone differs from those described previously in two respects: the strain from which the DNA originated $(D \times D / 1$ rather than strain $B$ ) and the method of its selection in which total MIC and total MAC DNA were used as probes. This DNA clone (pT1008) as well as three others gave an intense response to the MIC probe and a minimal response to the MAC probe during colony hybridization [22]. Analysis of the seven subclones of pT1008 identified three families of repeated sequences clustered in the MIC genome which differed in their degree of repetition in MIC DNA and in the extent to which members of each family are eliminated in the MAC [22] (Table 4). Family A4-A5, present in only a few copies in the MIC, is completely eliminated as well as the C end of family C-B$\mathrm{A} 1$, which is present in many copies in the MIC. Facultatively persistent sequences occur in family $\mathrm{A} 2-\mathrm{A} 3$ and for some members of the $\mathrm{C}-\mathrm{B}-\mathrm{A} 1$ family when DNA subclones B or A1 were used as probes. The degree of persistence is correlated with how widely the sequences are distributed among the strains. Only a small percentage of $B$ or A1 fragments persist in a few strains whereas a larger proportion of A2-A3 fragments persist and they are observed in all or most all strains. However, an individual fragment is found in only some of the strains.

Relevant to these facultatively persistent sequences is the report of Karrer et al [24] in which some MIC-specific sequences are retained in the MAC of an amicronucleate mutant. Since amicronucleate cells in this species ordinarily die, Karrer proposes that the aberrantly persistent MIC sequences may perform some essential function usually carried out in the MIC. The behavior of the facultatively persistent sequences reported here may weaken the strength of the Karrer data by showing that the distinction between retained and eliminated sequences is not as tight as previously believed.

What are the factors that play a role in determining persistence of these sequences in the MAC? Our results suggest that there may be a genetic predispositon to persistence; however, the "noise" level is high with respect to which sequences actually persist in a particular MAC. These suggestions are supported by data from the MAC DNAs of cell lines of various inbred strains as well as caryonides, caryonidal subclones, and old cell lines originating from crosses of $\mathrm{D} \times \mathrm{D} / 1$.

A genetic factor determining the persistence of sequences normally eliminated from the MAC can be seen in the data obtained from the inbred strains. Cell lines from the inbred strains have several MAC fragments in common when hybridized with the A2-A3 family (Table 2). For instance, cell lines from inbred strain B share several fragments, including the 5.2-, 1.65-, 0.65-, and 0.48/0.45-kb fragments. In general, similarities in the A2-A3 banding patterns of various cell lines reflect the genetic relationships of these inbred strains $[9,26]$. Observations on the C-B-Al family also support the idea that there is a genetic basis to the sequences which persist in the MAC (Tables 3, 4). DNA subclone C is MIC specific in all the inbred strains examined. DNA subclone B as well as DNA subclone A1 hybridize strongly to a few fragments in strains C3, D, D/1, and DI. Some of these fragments appear in both D and $\mathrm{D} / 1$, strains which are congenic [27]. Thus, there appears to be some relationship between the pattern of fragments that persist in the MAC and the genetic similarity of these strains. This relationship suggests that particular fragments have a genetic predisposition to be retained in the MAC.

While the above data suggest a genetic predisposition for certain sequences to persist, variability of pattern is evident among the cell lines tested. The MAC patterns 
TABLE 4. Destiny of MIC Sequences During MAC Development

\begin{tabular}{|c|c|c|c|c|c|}
\hline \multirow[b]{2}{*}{$\begin{array}{l}\text { Sub- } \\
\text { family }\end{array}$} & \multirow[b]{2}{*}{$\begin{array}{c}\text { No. } \\
\text { copies } \\
\text { in MIC }\end{array}$} & \multirow[b]{2}{*}{$\begin{array}{l}\text { No. fragments } \\
\text { that persist } \\
\text { in MAC }\end{array}$} & \multirow[b]{2}{*}{$\begin{array}{c}\text { Degree of } \\
\text { persistence } \\
(\%)\end{array}$} & \multicolumn{2}{|c|}{ Persistence in cell lines } \\
\hline & & & & $\begin{array}{c}\text { of any } \\
\text { subfamily } \\
\text { member }\end{array}$ & $\begin{array}{c}\text { of a } \\
\text { particular } \\
\text { fragment }\end{array}$ \\
\hline C & $200-300$ & 0 & $0 \%$ & - & - \\
\hline \multirow[t]{2}{*}{ B } & $200-300$ & $3-8$ & $1-4 \%$ & $\begin{array}{l}\text { 3: very } \\
\text { faint in } \\
\text { all strains }\end{array}$ & $\begin{array}{l}\text { Each fragment } \\
\text { found in all } \\
\text { strains }\end{array}$ \\
\hline & & & & $\begin{array}{l}\text { 5: only in } \\
\text { C3, D, D/1, } \\
\text { DI }\end{array}$ & $\begin{array}{l}\text { Variability: Each } \\
\text { fragment found in } \\
\text { only some strains }\end{array}$ \\
\hline $\mathrm{A} 1$ & $200-300$ & $0-7$ & $0-4 \%$ & $\begin{array}{l}\text { Only in C3, } \\
D, D / 1, D I\end{array}$ & $\begin{array}{l}\text { Variability: Each } \\
\text { fragment found in } \\
\text { only some strains }\end{array}$ \\
\hline A2 & $30-50$ & 3-9 & $6-30 \%$ & All strains & $\begin{array}{l}\text { Variability: Each } \\
\text { fragment found in } \\
\text { only some strains }\end{array}$ \\
\hline $\mathrm{A} 3$ & $30-50$ & $0-4$ & $0-13 \%$ & $\begin{array}{l}\text { All strains } \\
\text { except A }\end{array}$ & $\begin{array}{l}\text { Variability: Each } \\
\text { fragment found in } \\
\text { only some strains }\end{array}$ \\
\hline A4 & 4 & 0 & $0 \%$ & - & - \\
\hline A5 & 3 & 0 & $0 \%$ & - & - \\
\hline
\end{tabular}

of all the inbred strain cell lines are distinct for the A2-A3 family (Table 2). For example, cell lines BX2 and BX6 are genetically identical because of genomic exclusion [reviewed in 9] yet their banding patterns are different. The differences in banding patterns could have arisen during MAC formatin, since BX2 and BX6 have MACs that were formed independently. Likewise, $\mathrm{B} 7(\mathrm{~N}$ or $\mathrm{B})$ and $\mathrm{B} 4$ are genetically identical since they were derived from the same mating pair; yet, their patterns are different, again suggesting that the variation in pattern was introduced during MAC formation. The banding patterns of the C-B-A1 family are also variable in the MAC among the strains (Table 3). Thus, using probes for both repetitive families A2-A3 and C-B-A1, we have observed a large amount of variation in the MAC among cell lines of different inbred strains, as well as variation in banding pattern among cell lines within a given strain, as seen for strain B or for various cell lines of strain D (data not shown). We have also observed variation in banding patterns among genetically identical cell lines such as BX2 and BX6 or B7 and B4. These variations suggest that either there is residual heterozygosity within the inbred strains or, more likely, that epigenetic variability is introduced as the MAC is formed.

This epigenetic variability is also seen for the MACs of the old cell lines of D $\times \mathrm{D} / 1$ (Fig. 6). Variable banding patterns are seen for both repetitive families. Since 
$\mathrm{D}$ and $\mathrm{D} / 1$ are congenic strains, there should be little residual heterozygosity remaining between the two parental lines.

Further evidence for epigenetic variability is illustrated by the two sets of caryonides. Both the A2-A3 family (Fig. 3) and the C-B-A1 family (Fig. 4) show variation in their banding patterns for each of the four caryonides from two different sets. Most variation is seen when DNA subclone A1 is used as a probe: caryonides 31 A, 31B, and 31D each have an A1 Mbo I band different in size, and 31C does not appear to hybridize to $\mathrm{A} 1$ at all. Caryonides $42 \mathrm{~A}-\mathrm{D}$ vary both in the number of bands present as well as the sizes of these fragments. Since the four caryonides from a single mating pair are identical in their MIC genotype but each caryonide has an independently formed MAC, the observed difference in banding pattern within a set shows that the fragments that actually persist at one or more sites in the MIC genome varies. Moreover, the "noise" level generated by epigenetic variation appears to be high.

When is epigenetic variability introduced? Obviously, it occurs during MAC development in the four caryonides. Theoretically, it could occur exclusively or mainly during MAC development, or it could arise throughout clonal life. Continued processing of MAC DNA throughout clonal life has recently been observed with fragments containing 5S rDNA gene clusters [39] which were altered in size during vegetative growth: some fragments were lost as new fragments appeared. Vegetative processing of MAC DNA could explain the loss of persistent MAC sequences here also; for example, a band which hybridizes to DNA subclone A1 is lost from the 31D caryonidal cell lineage at about 75 fissions, and a new band appears (Fig. 5). However, changes in pattern appear to be less common during vegetative growth for these facultatively persistent sequences than for the $5 \mathrm{~S}$ genes. Only modest changes in pattern are seen for the caryonidal subclones when probed with A2 or A3 (data not shown) or with A1 (Fig. 5). Moreover, each established cell clone is completely stable in its particular pattern. Cell lines B7N and B7B are samples of an original cell line B-18687 obtained from different laboratories. Their banding patterns are identical, suggesting that their MACs have not changed since the two lines were separated several years ago. The six old cell lines were obtained from a cross of $D \times D / 1$. From each of these six cell lines, three subclones were isolated, and pT1008 was used as a probe against MAC DNA blots of the subclones (data not shown). In all cases the banding patterns of the three subclones were identical to the banding pattern of the old cell line from which they were taken. Thus, most of the epigenetic variability appears to be introduced during the development of the MAC, since major differences in pattern are observed among the caryonides.

What is the nature of this epigenetic heterogeneity? Theoretically, the fragments that persist could reflect alternative arrangements of a particular MIC segment or they could represent persistence of different MIC segments. Since repetitive sequences are involved, it is not possible to decide between these alternatives. Where one fragment, or none, is involved, as observed for the 31 set of caryonides probed with A1 (Fig. 4), we could imagine that a single site was involved. For the 42 set of caryonides three to four A1 fragments persist in three of the caryonides, and one Al fragment in the fourth caryonide (Fig. 4). Observation of three to four fragments of different size in a single MAC could be attributed either to the persistence of this family at three to four different locations in the MIC genome, or to alternative processing of a sequence at a single locus in the MIC genome with three to four different products appearing 
among the 45 copies of this locus in the MAC. If alternative ways of processing a MIC segment yield different products in a single MAC during its development, then we would expect to observe phenotypic assortment for these products during clonal life. This may indeed be the explanation for some of the changes seen among the caryonidal subclones.

Better evidence for alternative processing of a single MIC segment during MAC development has been obtained by examining a cloned MAC fragment that contains a persistent sequence (a member of the C-B-A1 family) as well as a sequence normally retained and present in single copy in the MAC [40]. This cloned fragment was used to construct MAC restriction maps of this region in cell lines whose MACs do, or do not, contain the persistent sequence. Extensive variation in the map flanking this region was observed. Moreover, when a set of four caryonides was probed with the subclone of the cloned MAC fragment that contained the single copy sequence, each of the caryonides had a different major fragment in its MAC.

In this paper we have identified sequences that are retained in some cell lineages but eliminated in others. Factors affecting these facultatively persistent sequences include a genetic predisposition to persist as well as epigenetic variability. This genetic predisposition may involve the process of elimination itself. Sequences that are invariably eliminated during MAC development appear to be removed by active degradation rather than passive underreplication and dilution [41]. Thus, the facultatively persistent sequences probably do not represent sequences being diluted out during normal elimination but, instead, the sequences are not excised at the site of elimination. The genetic predisposition to persist in the MAC may reflect the fact that some sequences are more likely to be missed by the elimination process. This might occur because they have a weak or less accessible signal for processing at these sites. The variability introduced during MAC formation may result from differences in the quality or accessibility of the processing signal, or from the influence of neighboring sequences, at a particular site in different MACs. If the quality or accessibility varied within a single MAC, the 45 copies of this MIC segment may be processed differently, resulting in a heterozygous $\mathrm{MAC}$ in which the heterozygosity is resolved by phenotypic assortment. Even at sites where elimination is complete and occurs as a result of precise internal deletions, one of the deletions appears to be generated in alternative ways, according to Austerberry et al [42]. Moreover, both the products generated by alternative splicing appear together in the MAC before assortment [42].

Several functions have been suggested for eliminated sequences. These sequences could specify MIC chromosomal functions such as centromeres, or sequences necessary for mitosis or meiosis. This is one interpretation for the presence of MICspecific sequences in the MAC of the amicronucleate mutant [24]. Alternatively, they could inactivate genes in the MIC. In that case, their elimination could result in gene activation in the MAC. While this study does not specifically address these possibilities, the sequences that do persist in the MAC do not appear to hinder MAC functions significantly (i.e., the cells survive). The B-Al sequences do not appear to be necessary for MAC function since any particular MAC sequence may, or may not, be present in those few cell lines in which persistence occurs. However, at least one member of the A2-A3 fasmily persists in the MAC of all cell lines. Thus, this sequence may be necessary for MAC function, provided it does not matter where the sequence is located in the MIC genome. Whatever the function of these facultatively persistent sequences, it does not require complete elimination, but rather allows 
certain of these sequences to persist in the MAC without affecting the normal functions of the MIC and, most likely, the MAC.

\section{CONCLUSIONS}

We have identified a class of sequences in $T$ thermophila that is retained in some cell lines but eliminated in others during somatic nuclear (MAC) development. These facultatively persistent sequences are found together with totally eliminated sequences on a cloned MIC DNA fragment that contains three families of sequences with different levels of repetition in the MIC genome. Two of the families contain members that exhibit facultative persistence. By examining the MAC of cell lines from a variety of sources, including several inbred strains, two sets of caryonides, caryonidal subclones, and vegetatively aged cell clones, we conclude that there is a genetic predisposition for these sequences to persist but that epigenetic variation may be introduced as the MAC develops, and polymorphisms may be generated if alternative processing of a single MIC segment occurs within a developing MAC. These polymorphisms could then be resolved by phenotypic assortment during vegetative growth. An interpretation of these observations is that the persistent MAC sequences persist because of weak or less accessible signals for processing at sites of elimination. The genetic component may reflect the fact that some sequences are more likely to be missed by the elimination process, whereas the variability introduced during MAC formation may result from differences in the quality or accessibility of the processing signal in that particular MAC. Whatever the function of these facultatively persistent sequences, it does not require complete and precise elimination so that persistence of these sequences in the MAC does not affect the normal functions of the MIC and, most likely, the MAC.

\section{ACKNOWLEDGMENTS}

This work was supported by research grants GM-27703 from the National Institute of General Medical Sciences, U.S. Public Health Service, and PCM-8300502 from the National Sciences Foundation. T.C.W. was supported in part by fellowships from the Rackham Graduate School and from the University of Michigan Cancer Institute. We thank Peter J. Bruns, David L. Nanney, and Les Jenkins for supplying several of the strains used in this study, Ning C. McLaren and Paul R. Ervin for nuclear isolations, and Almuth $\mathrm{H}$. Tschunko for her comments on the manuscript and help with Figures 1 and 4.

\section{REFERENCES}

1. Wilson EB (1928): The Cell in Development and Heredity. Third edition. New York, NY: Macmillan, pp. 323-328.

2. Prescott DM, Murti KG (1974): Chromosome structure in ciliated protozoans. Cold Spring Harbor Symp Quant Biol 38:609-618.

3. Yao MC, Gorovsky MA (1974): Comparison of the sequences of macro- and micronuclear DNA of Tetrahymena pyriformis. Chromosoma 48:1-18.

4. Beerman S (1977): The diminution of heterochromatic chromosomal segments in Cyclops (Crustacea, Copepoda). Chromosoma 60:297-344. 
5. White MJD (1973): Animal Cytology and Evolution. Third edition Cambridge, England: Cambridge University Press, pp. 500-546.

6. Tonegawa $S$ (1983): Somatic generation of antibody diversity. Nature 302:575-581.

7. Borst P, Cross GAM (1982): Molecular basis for trypanosome antigenic variation. Cell 29:291303.

8. Nasmyth KA (1982): Molecular genetics of ycast mating type. Annu Rev Genet 16:439-500.

9. Allen SL, Gibson I (1973): Genetics of Tetrahymena. In AM Elliott (ed): Biology of Tetrahymena. Stroudsburg, Pa: Dowden, Hutchinson and Ross, pp. 307-373.

10. Orias E (1982): Probable somatic DNA rearrangements in mating type determination in Tetrahymena thermophila: A review and a model. Dev Genet 2:185-202.

11. Altschuler MI, Yao MC (1985): The size of macronuclear DNA in Tetrahymena thermophila. Genetics 110:s82.

12. Orias E, Baum MP (1985): Mating type differentiation in Tetrahymena thermophila: Characterization of the delayed refeeding effect and its implications concerning intranuclear coordination. Dev Genet 5:141-156.

13. Iwamura Y, Sakai M, Mita T, Muramatsu M (1979): Unequal gene amplification and transcription in the macronucleus of Tetrahymena pyriformis. Biochemistry 18:5289-5294.

14. Yan MC (1981): Ribosomal RNA gene amplification in Tetrahymena may be associated with chromosome breakage and DNA elimination. Cell 24:765-774.

15. Yao MC, Zhu SG, Yao CH (1985): Gene amplification in Tetrahymena thermophila: Formation of extrachromosomal palindromic genes coding for rRNA. Mol Cell Biol 5:1260-1267.

16. Brunk CF, Tsao SGS, Diamond CH, Ohasi PS, Tsao NNG, Pearlman RE (1982): Reorganization of unique and repetitive sequences during nuclear development in Tetrahymena thermophila. Can $\mathrm{J}$ Biochem 60:847-853.

17. Yao MC (1982): Elimination of specific DNA sequences from the somatic nucleus of the ciliate Tetrahymena. J Cell Biol 92:783-789.

18. Yao MC, Yao CH (1981): Repeated hexanucleotide C-C-C-C-A-A is present near free ends of macronuclear DNA of Tetrahymena. Proc Natl Acad Sci USA 78:7436-7439.

19. Yao MC, Choi J, Yokoyama S, Austerberry CF, Yao CH (1984): DNA elimination in Tetrahymena: A developmental process involving extensive breakage and rejoining of DNA at defined sites. Cell 36:433-440,

20. Callahan RC, Shalke G, Gorovsky, MA (1984): Developmental rearrangements associated with a single type of expressed $\alpha$-tubulin gene in Tetrahymena. Cell 36:441-446.

21. Yokoyama R, Yao MC (1984): Internal micronuclear DNA regions which include sequences homologous to macronuclear telomeres are deleted during development in Tetrahymena. Nucleic Acids Res 12:6103-6116.

22. White TC, El-Gewely MR, Allen SL (1985): Eliminated Sequences with different copy numbers clustered in the micronuclear genome of Tetrahymena thermophila. Mol Gen Genet (in press).

23. Karrer KM (1983): Germ-line specific DNA sequences are present on all five micronuclear chromosomes in Tetrahymena thermophila. Mol Cell Biol 3:1909-1919.

24. Karrer K, Stein-Gavens S, Allitto BA (1984): Micronucleus-specific DNA sequences in an amicronucleate mutant of Tetrahymena. Dev Biol 105:121-129.

25. Iwamura Y, Sakai M, Muramatsu M (1982): Rearrangement of repeated DNA sequences during development of macronucleus in Tetrahymena thermophila. Nucleic Acids Res 10:4279-4291.

26. Allen SL, Ervin PR, McLaren NC, Brand RE (1984): The 5S ribosomal RNA gene clusters in Tetrahymena thermophila: Strain differences, chromosomal locations, and loss during micronuclear ageing. Mol Gen Genet 197:244-253.

27. Allen SL, Lee PHT (1971): The preparation of congenic strains of Tetrahymena. J Protozool 18:214-218.

28. Allen SL, White TC, Langmore JP, Swancutt MA (1983): Highly purified micro- and macronuclei from Tetrahymena thermophila isolated by percoll gradients. J Protozool 30:21-30.

29. Gunsalus RP, Zurawski G, Yanofsky C (1979): Stuctural and functional analysis of cloned deoxyribonucleic acid containing the trpR-thr regions of the Escherichia coli chromosome. J Bacteriol 140:106-113.

30. Maniatis T, Jeffrey A, Kleid AG (1975): Nucleotide sequence of the rightward operator of phage $\gamma$. Proc Natl Acad Sci USA 72:1184-1188.

31. Rigby PWJ, Dieckman M, Rhodes C, Berg P (1977): Labeling deoxyribonucleic acid to higher specific activity in vitro by nick translation with DNA polymerase I. J Mol Biol 113:237-251. 
32. Maniatis T, Fritsch EF, Sambrock J (1982): Molecular Cloning: A Laboratory Manual. Cold Spring Harbor, NY: Cold Spring Harbor Laboratory, pp. 98-101.

33. Helling RB, Goodman HM, Boyer HW (1974): Analysis of endonuclease R Eco Rl fragments of DNA from lambdoid bacteriophage and other viruses by agarose gel electrophoresis. J Virol 14: 1235-1244.

34. McDonell MW, Simon MN, Studier FW (1977): Analysis of restriction fragments of T7 DNA and determination of molecular weights by electrophoresis in neutral and alkaline gels. J Mol Biol 110:119-146.

35. Peacock AC, Dingham CW (1968): Molecular weight estimation and separation of ribonucleic acid by electrophoresis in agarose-acrylamide composite gels. Biochemistry 7:668-674.

36. Southern E (1975): Detection of specific sequences among DNA fragments separated by gel electrophoresis. J Mol Biol 98:593-517.

37. Allen SL, Gibson I (1972): Genome amplification and gene expression in the ciliate macronucleus. Biochem Genet 6:293-313.

38. Denhardt D (1966): A membrane-filter technique for the detection of complementary DNA. Biochem Biophys Res Comm 23:641-652.

39. Allen SL, Ervin PR, White TC, McLaren NC (1985): Rearrangement of the 5S ribosomal RNA gene clusters during the development and replication of the macronucleus in Tetrahymena thermophila. Dev Genet 5:181-200.

40. White TC, Allen SL (1985): Alternative processing of sequences during macronuclear development in Tetrahymena thermophila. Submitted to J Protozool.

41. Brunk CF, Conover RK (1985): Elimination of micronuclear specific DNA sequences early in anlagen development. Mol Cell Biol 5:93-98.

42. Austerberry CF, Allis CD, Yao MC (1984): Specific DNA rearrangements in synchronously developing nuclei of Tetrahymena. Proc Natl Acad Sci USA 81:7383-7387. 